Teologia i Moralność, volumen 13(2018), numer 2(24)

doi: 10.14746/tim.2018.24.2.5

\author{
AUGUSTO SARMIENTO \\ Facultad de Teología \\ Universidad de Navarra (España)
}

\title{
Humanae vitae: una encíclica profética
}

Calificada como encíclica profética, desde su publicación, los años transcurridos son una gran oportunidad para comprobar la perenne actualidad de su contenido y, a la vez, para subrayar la riqueza de la verdad que proclama. Lo hacía notar Juan Pablo II, hablando a los representantes de las Conferencias Episcopales con motivo del XX Aniversario de la publicación de Humanae vitae: "los años posteriores a la Encíclica -decía Juan Pablo II-, a pesar de la persistencia de las críticas injustificadas y de silencios inaceptables, han podido demostrar con claridad creciente que el documento de Pablo VI fue siempre no solo de palpitante actualidad sino rico de un significado profético". De esa actualidad y significado - continuaba el Papa-

un testimonio de particular valor ha sido ofrecido por los obispos en el Sínodo de 1980, que, en la proposición 22, se expresaba en estos términos: «Este sagrado Sínodo, reunido en la unidad de la fe con el sucesor de Pedro, firmemente defiende lo que en el Concilio Vaticano II (cfr. Gaudium et spes, 50) y, seguidamente en la Encíclica 'Humanae vitae' es propuesto y, en particular, que el amor conyugal debe ser plenamente humano, exclusivo y abierto a la vida (Humanae vitae, 11 y cfr. nn. 9 y 12$)^{1}$.

\footnotetext{
${ }^{1}$ Juan Pablo II, A los representantes de las Conferencias Episcopales en el XX Aniversario de la Humanae vitae (7.XI.1988), n. 3, en A. Sarmiento y J. Escrivá-Ivars, Enchiridion Familiae. Textos del Magisterio Pontificio y Conciliar (Siglos I a XX), III, Eunsa Pamplona 2003 (2 edic.), pp. 4906-4907 (En adelante: EF). Otros testimonios de Juan Pablo II sobre este carácter profético de la En-
} 
Los 50 años transcurridos muestran claramente, entre otras cosas, que el rechazo de la Encíclica conduce no solo a la banalización de la sexualidad sino a la pérdida de la verdad del amor humano y de la misma vida humana. Conduce, en efecto, a una valoración de la vida humana que ya no se respeta por sí misma, sino por su "calidad", que, en la mayoría de los casos, se identifica con su utilidad. Desemboca, por eso, en una negación de la persona -en una ética de la persona sin la persona-, en el dominio de los débiles por los poderosos, etc.

El título del tema que se me ha encomendado - "Humanae vitae: una encíclica profética" - señala ya la perspectiva desde la que voy a presentar esta reflexión sobre la Encíclica y que, con la venia de Ustedes, desarrollaré en tres partes. En la primera -Una encíclica profética-, con trazos muy breves y generales -son solo unas pinceladas - se pretende justificar ese carácter profético o visión de futuro. Esa reflexión se continúa en la segunda parte -Una norma antigua y nueva - con la consideración de la respuesta que la Encíclica da a la cuestión entonces planteada: la de la moralidad de la regulación de la natalidad mediante la separación, sirviéndose de fármacos anovulatorios, de los significados unitivo y procreador del acto conyugal. Al final, en la tercera parte -Una visión global del hombre y de su vocación-se ofrecen algunas consideraciones sobre algunas de las claves necesarias y fundamentales para lectura y recepción de la Encíclica, según han puesto sobradamente de relieve los cincuenta años que han pasado desde su publicación. Me refiero a la necesidad de partir de una visión antropológica adecuada.

\section{Primera parte: Una encíclica profética}

Son tres los pasos que en el desarrollo de esta parte. El primero, con el título El porqué de "Humanae vitae, busca dar razón de algunos de los motivos que llevaron a Pablo VI a publicar la Encíclica. El segundo -Signo de contradicción - es una presentación, a modo de síntesis, de las reacciones a favor $\mathrm{y}$ en contra del texto del Papa; se hace también una consideración de algunas de las consecuencias de esas críticas. Finalmente - es el tercer paso o apartado: ¿Ruptura o continuidad? - , se ofrece un apunte sobre la continuidad y novedad de la enseñanza de Humanae vitae con las enseñanzas del Magisterio anterior - de manera particular con el Vaticano II - y también del Magisterio posterior. En todo caso, parece oportuno advertir que el tratamiento dado a las cuestiones

cíclica: A los Obispos austríacos (19.VI.1987), n. 5, en EF, V, p. 4711; En la clausura de la V Asamblea General del Sínodo de los Obispos (25.X.1980), n. 8, en EF, III, pp. 2888-2890; Exhortación Apostólica Familiaris consortio (22.XI.1981), n. 29; A los participantes en el II Congreso de Teología Moral sobre la Humanae vitae (12.XI.1988), nn. 1-8, en EF, V, pp. 4919-4930; A los Cardenales y Prelados de la Curia Romana (22.XII.1988), n. 4, en EF, V, pp. 4931-4933. 
consideradas en esta parteno se limita a ser una descripción de lo que por entonces tenía lugar en relación con los problemas abordados en la Encíclica. El interés primero es constatar cómo se han hecho realidad las consecuencias de esa doctrina, previstas y apuntadas ya por la Encíclica.

\section{El porqué de "Humanae vitae"}

No parece aventurado afirmar que, entre los factores que motivaron la publicación de Humanae vitae, cabe apuntar, por lo que se refiere a la sexualidad, la difusión de una mentalidad, cada vez más cresciente, favorable a la contracepción. Se debía, entre otros factores, a la presión ejercida por el contexto socioeconómico en el modo de abordar - preferentemente con categorías y cálculos económicos - los temas de la fecundidad y de los nuevos nacimientos. Se ha de tener cuenta además el hecho de que por esos años -en 1968 - tuvo lugar la explosión de la así llamada "revolución sexual", que no solo reivindicaba para el individuo el derecho al placer sexual, sino también el derecho de cada uno a hacer de sí mismo el criterio último de la moralidad, por encima e, incluso, en contra de las reglas objetivas ordenadoras de la convivencia social.

La difusión de esa mentalidad -se percibe enseguida — no podía conducir más que a una exaltación desmesurada de la subjetividad autónoma del hombre y de su libertad; y, a la larga, a la abolición de la personalidad consciente, porque es evidente que la persona, liberada de sus instintos y sin referencia a la trascendencia, acaba por ser totalmente manipulable. «Una vez declarado legítimo escindir el uso de la sexualidad de la procreación, resulta problemático justificar la afirmación de que el uso de la sexualidad sólo es lícito entre los cónyuges, abriéndose así el camino a la posibilidad de separar legítimamente el uso de la sexualidad del matrimonio; el paso ulterior será separarlo también del amor y, finalmente, de la exigencia, a estas alturas ya no sostenible, de la diferencia sexual de los dos componentes de la pareja. Resulta entonces legítimo y lógico afirmar que cualquier tipo de actividad sexual nada tiene que ver con la moral. Estos juicios se ven confirmados por la promiscuidad sexual extendida por todas partes y por las nuevas enfermedades de transmisión sexual» ${ }^{2}$.

Pasados cincuenta años desde la publicación de la Encíclica, a nadie le parece exagerado lo que entonces afirmaba Pablo VI:

Consideren, antes que nada, el camino fácil y amplio que se abriría a la infidelidad conyugal y a la degradación general de la moralidad. [...] Podría también temerse

\footnotetext{
${ }^{2}$ Conferencia Episcopal Española, "Humanae vitae”. Una encíclica profética (20.IX.1992), n. 10
} 
que el hombre, habituándose al uso de las prácticas anticonceptivas, acabase por perder el respeto a la mujer y, sin preocuparse más de su equilibrio físico y fisiológico, llegase a considerarla como simple instrumento de goce egoístico y no como a compañera, respetada y amada» (HV, n. 17).

El correr de los años ha mostrado también sobradamente quela contracepción provocaría no sólo la destrucción del amor humano con el consiguiente perjuicio para los mismos cónyuges y para sus hijos, sino una alarmante disminución de los nacimientos y a la vez una multiplicación difícil de imaginar del número de abortos. En definitiva, a la destrucción de la vida misma. Es el término en el que, por su propia dinámica, desemboca inexorablemente la contracepción, que lleva a buscar la reproducción de la vida independientemente del ejercicio de la sexualidad. La "lógica" de la mentalidad contraceptiva termina, más pronto que tarde, en la difusión de una cultura de muerte. El paso del tiempo ha puesto de manifiesto que lo que comenzó -en no pocos casos, como una pretendida ayuda -primero a la regulación de la natalidad (fármacos, intervenciones quirúrgicas, etc.), después a la transmisión de la vida (reproducción asistida, etc.) - ha llevado a la difusión de una mentalidad, que ya no reconoce el valor de la vida humana por sí misma, sino en función de su utilidad. Lo que determina el valor de la vida es su "calidad". Hay vidas que no merecen ser vividas. Lo que se debe hacer es suprimirlas (deficientes, enfermos terminales, etc.). Lo exige el bien de los que se encuentran en esas situaciones, el entorno familiar, la sociedad que se librará de costes innecesarios, etc.

Otro de los motivos que estuvieron detrás de la Encíclica fue, en mi opinión, el hecho de que, por aquellos años, también en algunos ambientes católicos, a la vista de los informes sobre el crecimiento de la población y, conocidos los progresos de la ciencia en el control de la fertilidad femenina, se sugería la conveniencia -también la necesidad- de una reconsideración de la doctrina de la Iglesia sobre la contracepción. En determinados círculos teológicos se sostenía que las enseñanzas y normas de la Iglesia sobre la procreación no se deducen inmediatamente de la Revelación y sobre las que, por tanto, no cabría una intervención definitiva de la autoridad de la Iglesia. Por otra parte, otros autores defendían que el uso de los anovulatorios -la "píldora" era el tema concreto que se debatía - no interferiría en la fisiología de la relación conyugal; $\mathrm{y}$, además, pondría a disposición de los esposos un medio seguro para llevar a cabo una verdadera paternidad responsable. ¿No habría llegado ya la hora de proclamar la licitud de la así llamada "píldora"?³. Son los argu-

\footnotetext{
${ }^{3}$ Una relación de estas posiciones sobre el recurso a los fármacos contraceptivos en base a una referencia al lenguaje interpersonal de la sexualidad, en el contexto del matrimonio, puede encontrarse en Valsecchi 1968; Böckle 1965, pp. 101-129. Al respecto escribe Alburquerque 2004, p. 140:
} 
mentos reunidos en gran parte en la Encíclica y que serían prolongados en los años posteriores por esos y otros autores.

Humanae vitae fue, ciertamente, la respuesta concreta de la Iglesia a una cuestión particular de ética sexual: "la conexión inseparable de los significados unitivo y procreador del acto conyugal". Pero, sobre todo, significó entonces -y lo sigue significando ahora - una propuesta clara y explícita del valor y dignidad de la vida humana y de la verdad y de la belleza del amor conyugal. Una enseñanza, que, como ya entonces se advertía y más adelante se comprobaría, pone en juego muchos y vitales aspectos de la moral cristiana y de la ética humana. "Está en juego la defensa de lo 'humano' en una de sus dimensiones fundamentales". Y cuando se "llegan a tocar aspectos fundamentales de lo 'humano', la dignidad misma de la persona es puesta en tela de juicio, es acechada y queda también comprometida" (Cfr. Juan Pablo II, A los Cardenales y Prelados de la Curia Romana (22.XII.1988), n. 4, en EF, V, pp. 4932).

Detrás de las cuestiones concretas afrontadas por la Encíclica, se advierte que lo que está en juego en el tema del debate - lo señalaba ya la Encíclica- es abrir la puerta a una concepción del hombre que considera a éste señor absoluto y dueño sin condiciones de su propio cuerpo y de la realidad que le rodea. Y si la voluntad humana, desvinculada de su referencia al Creador, se convierte en la norma última de la moralidad, los bienes de la vida y de la sexualidad dependerán de lo que la persona decida, que, como es evidente, cambiará según sean los gustos de cada momento. En este sentido, Humanae vitae advertía proféticamente que, «si no se quiere exponer al arbitrio de los hombres la misión de generar la vida, se deben reconocer los límites infranqueables a la posibilidad de dominio del hombre sobre el propio cuerpo y sobre sus funciones, límites que a ningún hombre le es lícito franquear» (HV, n. 17). La historia de los años transcurridos ha puesto de manifiesto que con esas dudas se iniciaba un proceso, que, según ha advertido también Veritatis splendor en referencia a la década de los noventa, describirá como "una nueva situación dentro de la misma comunidad cristiana [...] "se pone en tela de juicio, de modo global y sistemático, el matrimonio moral" (Juan Pablo II, Enc. Verita-

«La argumentación teológica que se muestra favorable en estos momentos a la utilización de métodos anticonceptivos farmacológicos se expresa principalmente en cuatro direcciones. Por una parte, se afirma que el uso de anticonceptivos farmacéuticos no es una infracción de la doctrina tradicional, porque con ellos no sufre menoscabo alguno la estructura del acto sexual (L. Janssens). Otros, como Auer o Reuss, enseñan que no existe ninguna diferencia moral radical entre el uso del método Ogino-Knauss y los otros métodos anticonceptivos. E. Schillebeecks ataca el fisicismo moral de los teólogos de la escuela tradicional, que elevan a criterio normativo la estructura biológico-fisiológica del acto sexual y la inviolabilidad del acto, para juzgar su integridad moral. J. David defiende que los actos sexuales particulares no deben ser considerados aisladamente, sino dentro del fin procreativo que tiene el conjunto de la vida conyugal. Estos argumentos han seguido estando presentes en el debate teológico, aún después de la promulgación de la "Humanae vitae"». 
tis splendor [6.VIII.1993], n. 4). Casi con las mismas palabras Juan Pablo II había constatado unos años antes, en 1988: "Los veinte años transcurridos han demostrado que [...] la vacilación o duda sobre la norma moral enseñada en la 'Humanae vitae' han implicado también otras fundamentales verdades de razón y de fe" (Juan Pablo II, Al II Congreso Internacional de Teología Moral [12.XI.1988], n. 3, en EF, V, pp. 4922-4993).

Con el fin de dar una respuesta a la cuestión -la ilicitud de los anovulatorios era la cuestión concreta debatida - Juan XXIII había constituido, en marzo de 1963, una Comisión para el estudio sobre la población, la familia y la natalidad. Una Comisión que Pablo VI confirmó y amplió en 1964 y cuyo objetivo era asesorar al Papa, quien quiso que la cuestión no se tratara en el Concilio, reservándose para él dar la respuesta definitiva ${ }^{4}$. Mientras tanto, la intensa campaña a favor de la contracepción, iniciada ya en tiempos de Juan XXIII al constituirse esa Comisión de estudio, se agudizó con la publicación por distintos medios del informe "secreto" de la Comisión para uso del Papa. En abril de 1967, a través de los medios de comunicación ("Le Monde", "The Tablet" y el "National Catholic Reporter") se da a conocer al gran público ese informe en el que la mayoría de los especialistas integrantes de esa Comisión se inclinaba abiertamente por una mitigación de la doctrina de la anticoncepción. Como señalaría después el mismo Papa, el informe hacía ver que en el seno de la Comisión, "no se había alcanzado una plena concordancia de juicios acerca de las normas morales a proponer"; y, lo que era más grave, "habían aflorado algunos criterios de soluciones que se separaban de la doctrina moral sobre el matrimonio propuesta por el Magisterio de la Iglesia con constante firmeza" (Cfr. HV, n. 6).

Estando así las cosas, según el mismo Papa confesaba en la audiencia general celebrada a los tres días de la publicación de Humanae vitae, después de haber "estudiado, leído, discutido cuanto podíamos" y de haber "rezado también mucho", "no hemos tenido duda alguna al decir que debíamos pronunciar nuestra sentencia en los términos expresados por la Encíclica" (Pablo VI, Audiencia general [31.VII.1968], nn. 3 y 6, en EF, III, pp. 1942-1945). Unos días más tarde, en el saludo del Ángelus, se refería a ese mismo deber y confirmaba que "hemos hablado por deber de nuestro oficio y por caridad pastoral" (Pablo VI, Audiencia general [4.VIII.1968], n. 4, en EF, III, p. 1948).

${ }^{4}$ Cfr. Concilio Vaticano II, Constitución Pastoral Gaudium et spes (7.XII.1965), 51, nota 14: "Ciertas cuestiones que necesitan más diligente investigación, han sido confiadas por orden del Sumo Pontífice, a la Comisión pro Estudio de Población, Familia y Natalidad, para que, cuando ésta acabe sutarea, el Sumo Pontífice dé su juicio. Permaneciendo así firme la doctrina del Magisterio, el Sínodo no pretende proponer inmediatamente soluciones concretas" (En adelante: GS). 


\section{Signo de contradicción}

La voz de Nuestra Encíclica Humanae vitae -decía Pablo VI a los pocos días de su publicación - ha tenido muchos ecos y, que recordemos, nunca han llegado al Papa tantos espontáneos mensajes de agradecimiento y de asentimiento por la publicación de un documento suyo como en esta ocasión, de todas las partes del mundo y de toda clase de personas. [...] Sabemos que hay también muchos que no han apreciado Nuestra enseñanza, incluso no pocos se le oponen. [Y añadía:] Queremos, una vez más, recordar cómo la norma por Nos reafirmada no es Nuestra, sino que es propia de las estructuras de la vida, del amor y de la dignidad humana; lo que quiere decir que deriva de la Ley de Dios. [...] Es solo una norma moral exigente y severa, hoy y siempre válida" (Ibídem, n. 1, en EF, III, p. 1947).

"A decir verdad - decía ya la Encíclica-, ésta [la Iglesia] no se maravilla de ser, a semejanza de su divino Fundador, signo de contradicción, pero no deja por esto de proclamar con humilde firmeza toda la ley moral, natural y evangélica" (Cfr. HV, n. 18).

La Encíclica contradecía abiertamente los gustos de un tiempo y una cultura que, en no pocos ambientes y lugares, caminaba en otra dirección. Pero no solo fuera del ámbito de la Iglesia Católica, también entre de los católicos tuvo lugar la incomprensión de muchos laicos y sobre todo la violenta oposición de influyentes grupos de teólogos; $\mathrm{y}$, por otra parte, la ambigua posición de algunas Conferencias Episcopales. A esa reacciones aludía, el Cardenal Ratzinger unas décadas después, en 1995: "Raramente un texto de la historia reciente del Magisterio se ha convertido en un signo de contradicción tan grande como esta encíclica, que Pablo VI escribió a raíz de una decisión profundamente sufrida".

Algunos episcopados, que, por una parte, daban la razón al Pontífice y, por otra, intentaban mitigar la enseñanza de la Encíclica. Aunquetodos los Episcopados sostenían que Humanae vitae no era un acto del ejercicio del Magisterio infalible, no eran, sin embargo, coincidentes en la interpretación de la naturaleza de ese magisterio. Para algunos Episcopados (España, Méjico, Polonia), que la doctrina de Humane vitae no se propusiera como infalible no podía interpretarse como si la doctrina que se proponía no fuera definitiva. Otros Episcopados (Suecia, Noruega, Finlandia, Dinamarca...) admitían que la enseñanza de Humanae vitae, al no proponerse como infalible, podría cambiar con el paso del tiempo. Y si no era una doctrina infalible -señalaban otros - podía haber lugar para el disentimiento, aunque con ciertas condiciones: la presunción ha de estar a favor del Magisterio (USA), las razones deben ser graves (Escandinavia), después de una consideración seria ante Dios (Bélgica), o un examen atento de los motivos del disenso (Canadá; Cfr. Hamel 1969, pp. 243-349). 
Se ha llegado a escribir que, según las declaraciones de los Episcopados, "los católicos de Oslo, Dublín, Bruselas, Manila, Madrid, Djakarta o París tendrían interpretaciones diversas".

Ciñéndonos ahora al ámbito teológico, una primera observación es que fueron varios las frentes y las razones que llevaron a no pocos teólogos a contestar -cuando no rechazar-la enseñanza de la Encíclica. Con todo, la generalidad de los autores coincide en señalar que la raíz de las diferentes reacciones (asentimiento o rechazo) ante la publicación de la Encíclica está, en la mayoría de los casos, en el modo de interpretar la autoridad y competencia del Magisterio de la Iglesia en las cuestiones de moral natural. Esta es, ciertamente, la cuestión de fondo. ¿Cuál es la naturaleza del Magisterio en las cuestiones de moral natural? ¿Es una limitación o negación del papel de la "razón"?

Si se parte de que el Magisterio, aunque puede pronunciarse sobre cuestiones morales en el ámbito humano, la autoridad y el carácter vinculante de sus pronunciamientos se debe a la fuerza o al valor probativo de su argumentación, se defenderá que lo "razonable" será el disenso (cuando no rechazo) en el caso de que los argumentos aducidos no convenzan o se piense que son más fuertes los que se presentan en contra. Esa fue la posición de un amplio sector en $\mathrm{USA}^{5}$, Alemania Occidental ${ }^{6}$, los Países Bajos ${ }^{7}$, por citar algunos ámbitos y países. Un testimonio claro de ese "rechazo" es la declaración al término de una reunión celebrada en Ámsterdan, en la que participaron 20 teólogos de Alemania, Bélgica, Francia, Holanda y otros países centroeuropeos ${ }^{8}$.

Frente a las reacciones de rechazo, otro amplio sector de teólogos (también en los países y ámbitos donde el disenso fue más amplio y vivo) se mostró a favor de la enseñanza de $H V$. Y más allá de las cuestiones o razonamientos particulares, dos son las direcciones en que se mueven. Una más general: la competencia del Magisterio en las cuestiones de moral. Otra: la necesidad de una interpretación adecuada de la ley natural. Vienen a ser el marco en el que apoyan la enseñanza de HV y también -casi siempre - desde el que dan res-

\footnotetext{
${ }^{5}$ Entre otros: J.A. Bracken, C.E. Curran, J.A. Komonchak, R. McCormick, etc. Puede consultarse a Angelia 2009, pp. 421-492.

${ }^{6}$ Es el caso de F. Böckle, L.M. Weber, K. Rahner, L. Gründel; cfr. Juza 2010, pp. 157-252.

${ }^{7}$ Algunos de esos autores son: W. Goddijn, E. Schillebecks, Th. Beemer, C.P. Sporken; cfr. Alonso 2014, pp. 317-398.

${ }^{8} \mathrm{Al}$ término de dos días de estudio y discusión tenidos en Amsterdam del 18 al 19 de setiembre de 1968 hicieron pública una Declaración -“Theologenberaad over 'Humanae vitae' in Amsterdam", 18-19 september 1968", en "Katholiek Archief” 23 (1968), pp. 1027-1031-, cuyos firmantes fueron J.M. Aubert, A. Auer, T. Beemer, F. Böckle, W. Bulst, R. Callewaert, M. De Wachter, S.J., E. Mc Donagh, O. Franssen, S.J., J. Groot, L. Janssens, W. Klijn, S.J., F. Klosternann, O. Madr, F. Malmberg, S.J., S. Pfürtner, O.P., C. Robert, P. Schoonenberg, S.J., C. Sporken, R. Van Kessel. También tuvo particular repercusión e influencia el artículo de K. Rahner, S.J., publicado en "Die Welt" el 26 de agosto de 1968 y traducido en "Il Regno".
} 
puesta a los argumentos de los que se oponen o rebajan la autoridad de la Encíclica. Sobre la competencia y autoridad del Magisterio en materia de moral humana y, ya en concreto, sobre la autoridad de HV sostienen claramente que es vinculante. Como se trata de temas de moral humana, el Papa tiene autoridad para pronunciarse y hacerlo con autoridad. Es una autoridad y competencia que no está ligada a la argumentación que se aduce ${ }^{9}$.

\section{2. ¿Ruptura o continuidad?}

Una de las críticas más frecuentes y graves dirigidas contra Humanae vitae era -y es - la de haberse apartado de la doctrina del Concilio Vaticano II sobre el amor conyugal y la paternidad responsable. Lo que se denuncia es que la Encíclica ha asumido una visión biologicista de la sexualidad al tratar del amor conyugal y de la paternidad responsable y, de esa manera, se ha apartado de la visión personalista adoptada por el Concilio. La acusación era de que la doctrina de la Encíclica era un"retroceso" o "vuelta atrás" respecto de Gaudium et spes ${ }^{10}$.

La realidad, sin embargo, es otra. Lo que se constata es que la doctrina de Humanae vitae, a la vez que se inscribe en la línea del Magisterio anterior al Concilio, profundiza y explicita la del Vaticano II (sobre todo Gaudium et spes) y es prolongada en el Magisterio posterior. Así lo demuestra los mismos documentos con sus referencias y citas: tanto las que se hacen desde la Encíclica, como las referencias que se hacen a ella, desde fuera de la Encíclica. Pero, sobre todo, la continuidad y profundización de la doctrina de Humanae vitae respecto de Gaudium et spes aparece clara por el análisis y comparación de los dos documentos.

La doctrina de Humanae vitae respecto del amor conyugal y la paternidad responsablemente ética no supone ninguna revolución respecto del Magisterio anterior al Concilio ni tampoco una vuelta atrás con relación a Gaudium et spes. Son significativos, en este sentido, los textos del Magisterio anterior a Humanae vitae - a propósito de "la competencia del Magisterio"-citados en la nota 4 de la Encíclica ${ }^{11}$, que reproduce en parte los referidos en la nota 14

${ }^{9}$ Se mueven en esta línea, junto a muchos otros, autores como B. Ashley, J.M. Boyle, J. Finnis, J. Ford, J.M. Smith, G. Grisez, L. Melina, M. Zalba, K. Wojtyla, T. Makowski, C. Caffarra, A. Scola, R. Tremblay, E. Smith, W.E. May, J. Ratzinger, R. García de Haro, etc. Además de la bibliografía ya citada sobre la recepción de la Encíclica en el ámbito teológico de Alemania, USA, Países Bajos puede verse también: para el área de Italia a Zenoni 2003, pp. 161-278; y para el área de Polonia a Zadworny 2013, pp. 393-473.

${ }^{10}$ Se mueve en esta línea, p. e., Fuchs 1970, p. 54.

${ }^{11}$ Las referencias de HV, n. 4, nota 4 son: Catechismus Romanus Concilii Tridentini, pars II, c. VIII; León XIII, Encíclica Arcanum (10.II.1880), nn. 1-28, en EF, I, pp. 481-516; Pío XI, Encícli- 
del n. 51 ("El amor conyugal debe armonizarse con el respeto a la vida humana") de Gaudium et spes ${ }^{12}$. Pablo VI propone de nuevo la visión antropológica y moral que Pío XI, en su encíclica sobre el matrimonio, y Pío XII, en numerosas alocuciones, había considerado como "doctrina cristiana enseñada desde los orígenes y nunca modificada".

Con relación a la continuidad y profundización de Humanae vitae respecto de Gaudium et spes, son de un valor particular las palabras del Papa reflejadas en la Encíclica cuando, en referencia a las "exigencias del amor conyugal y de una paternidad responsable", habla de la conveniencia de "precisar bien el verdadero concepto de estas dos grandes realidades de la vida matrimonial, remitiéndonos sobre todo a cuanto ha declarado, a este respecto, en forma altamente autorizada, el Concilio Vaticano II en la Constitución pastoral Gaudium et Spes (Cfr. HV, n. 7). «Estábamos obligados a hacer nuestra la enseñanza del Concilio, promulgado por Nos mismo... Hemos reflexionado sobre los elementos estables de la doctrina tradicional y vigente de la Iglesia y, en especial, sobre las enseñanzas del reciente Concilio» (Pablo VI, Audiencia general (31. VII.1988), nn. 3 y 6, en EF, III, pp. 1942-1945).

Significativas también son las numerosas y variadas afirmaciones de esa continuidad realizadas por Juan Pablo II en los más diversos contextos. Además de los textos de las alocuciones orientadas a esa finalidad ${ }^{13}$, parece de relevancia particular el Familiaris consortio:

De este modo, siguiendo la tradición viva de la comunidad eclesial a través de la historia, el reciente Concilio Vaticano II y el magisterio de mi predecesor Pablo VI, expresado en la encíclica Humanae vitae, han transmitido a nuestro tiempo un anuncio verdaderamente profético, que reafirma y propone de nuevo con claridad

ca Divini illius Magistri (31.XII.1929), nn. 25-58, en EF, I, pp. 697-706; Encíclica Casti connubii (30.XII.1930), nn. 1-137, en EF, I, pp. 709-794; Pío XII, Alocución a la Unión Italiana médicobiológica de San Lucas (12.XI.1944), nn. 25-28, en EF, II, pp. 1306-1310; Al Convenio de la Unión Católica Italiana de Comadronas (29.X.1951), nn. 1-71, en EF, II, pp. 1424-1462; Al Congreso del „Fronte della Famiglia” y de la Asociación de Familias Numerosas (26.XI.1951), nn. 1-19, en EF, II, pp. 1463-1474; Al VII Congreso de la Sociedad Internacional de Hematología (12.X.1958), en AAS 50 (1958), pp. 734-735; Juan XXIII, Encíclica Mater et Magistra, en AAS 53 (1961), pp. 446-447; Codex Iuris Canonici, can. 1067; 1068, párr. 1; 1076, párr. 1-2; Conc. Vaticano II, Const. Past. Gaudium et Spes, nn. 47-52.

${ }^{12}$ En GS, n. 51, n. 14 se cita a Pío XI, Encíclica Casti connubii (31.XII.1930), en AAS 22 (1930), pp. 545-546; Pío XII, A la Unión Italiana médico-biológica de San Lucas (12.XI.1944), nn. 25-28, en EF, II, pp. 1306-1310; Al Convenio de la Unión Católica Italiana de Comadronas (29. XI.1951), nn. 1-71, en EF, II, pp. 1424-1462; Al Congreso del „Fronte della Famiglia” y de la Asociación de Familias Numerosas (28.XI.1951) nn. 1-19, en EF, II, pp. 1463-1474; Al VII Congreso de la Sociedad Internacional de Hematología (12.X.1958), en AAS 50 (1958), pp. 734-735pp. 734-735.

${ }^{13}$ Juan Pablo dedica 16 audiencia generales, entre el 11 de julio y el 28 de noviembre de 1984 , a considerar esa continuidad y actualidad de la Encíclia (en EF, V, pp. 4139-4244). 
la doctrina y la norma, siempre antigua y siempre nueva, de la Iglesia sobre el matrimonio y la transmisión de la vida humana (FC, n. 29).

Aparte de esos argumentos externos o de autoridad existe también otra argumentación interna, es decir, a partir de la comparación entre los dos documentos, entre Humanae vitae y Gaudium et spes. Es la consideración del texto de la misma Encíclica la que afirma esa continuidad (Cfr. Felici 1986, pp. 1-25). El concepto de ley natural presente Humanae vitae es el que tiene en cuenta también Gaudium et spes: se habla de una ley natural, no biologicista sino inscrita en una naturaleza humana y que, por eso, es una persona. Como Gaudium et spes, la ley natural -la norma-, a la que se refiere Humanae vitae, es un ley o norma de la persona y, por tanto, es una norma personalista. Es natural porque se inscribe en el orden de los significados originarios inscritos en la naturaleza humana; y es personalista porque, al respetar la estructura propia de esos significados, ayuda a expresar correctamente su lenguaje, sirviendo a la perfección de la persona.

La verdad del lenguaje del cuerpo -referido a la relación conyugal- es percibida en la conciencia de la persona por la lectura de la verdad interior del acto conyugal. Eso quiere decir que, primero, es necesario captar una verdad ontológica referida a la estructura misma del acto; y, después, como consecuencia la verdad subjetiva que aprehende la verdad objetiva, es decir los significados. Dos son, por tanto las dimensiones del lenguaje de la sexualidad: una objetiva, que expresa la verdad intrínseca; y otra personalística o subjetiva, en la que se manifiesta, a sí misma y por sí misma, la persona singular. Dos verdades o dimensiones esenciales para la verdad del lenguaje de la sexualidad. Humanae vitae habla de una ley natural, expresión de la "ley eterna" e inscrita en la unidad de la persona humana, que por la Redención ha sido llamada y elevada al orden sobrenatural. Las intervenciones de Juan Pablo II acerca de esta materia han puesto de relieve cada vez más los aspectos personalistas de HV.

Humanae vitae sigue la línea de Gaudium et spes. Pero además constituye un desarrollo y es un complemento de esa Constitución. A propósito del problema de "armonía del amor humano con el respeto a la vida", Juan Pablo II hace notar cómo mientras Gaudium et spes "excluye toda "verdadera contradicción» en el orden normativo" (Gs, 51), Humanae vitae "habla no tanto de la «no-contradicción en el orden normativo, cuanto de la «inseparable conexión» entre la transmisión de la vida y el auténtico amor conyugal desde el punto de vista de los «dos significados del acto conyugal: el significado unitivo y el significado procreativo (HV, 12)" (Juan Pablo II, Audiencia general [25. VII.1984], n. 2, en EF, V, p. 4150). La Encíclica, además de dar luz sobre el sentido de esa no-contradicción, ofrece una motivación de esa norma moral, que hace ver su conformidad con la misma razón humana. 
Un marco y una luz que, en los años posteriores a la Encíclica, -se descubre fácilmente- está presente en las intervenciones del Magisterio de la Iglesia sobre las cuestiones sobre el amor y la vida humanos. En esta línea, son significativos, entre otros documentos -y de manera particular en relación con la vida humana - la instrucción Donum vitae, sobre el respeto de la vida humana naciente y la dignidad de la procreación (1987); la encíclica Evangelium vitae, sobre el valor inviolable de la vida humana (1995); y la instrucción Dignitas Personae, sobre algunas cuestiones de bioética (2008). Y más relacionados con el amor humano y conyaugal, la Exhortación Apostólica Familiaris consortio que, retomando la perspectiva antropológica y moral de Humanae vitae, profundiza en la consideración del amor conyugal, la paternidad responsable, en el contexto más amplio de la vocación y misión de la familia. Juan Pablo II vuelve sobre estas mismas cuestiones durante nueve audiencias, en 1984. Y ese es también el horizonte que está presente en Gratissimam sane (la Carta a las familias, 1994). Pero, sobre todo es significativo, por el significado que el Catecismo de la Iglesia Católica tiene como regula fidei, el recurso que allí se hace a Humanae vitae al tratar de la fecundidad del matrimonio (Cfr. CEC, nn. 2366-2372).

\section{Segunda Parte. Una norma antigua y nueva}

El desarrollo sobre el contenido de esta parte se hace como sigue. El primer apartado -El principio o la norma de la Humanae vitae: la cuestión plantea$d a$ - está dedicado a la consideración de la cuestión abordada directa y expresamente por la Encíclica. Viene después, en el apartado segundo-Una norma humano divina - una reflexión sobre la fundamentación de esa norma, sobre el alcance de lo que se quiere decir cuando se afirma que "está escrita en la naturaleza humana y confirmada por la Revelación". Por último, en el apartado tercero -La autoridad o valor vinculante - esa reflexión se prolonga desde la perspectiva de la competencia y autoridad del Magisterio en la cuestión, cuya respuesta ofrece la Encíclica.

\section{El "principio" o la norma de Humanae vitae: la cuestión planteada}

Cuando se publica Humanae vitae estaba bastante difundida - se puede decir que ese era el pensamiento común - la idea de que la anticoncepción consistía en manipular de algún modo la realización del acto conyugal. Y como la "píldora anovulatoria" (que como tal hoy casi no existe, porque la mayoría de los fármacos anticonceptivos tienen también otros efectos, además del ano- 
vulatorio) no modificaba la relación conyugal propia de ese acto, algunos se preguntaban si su uso debería considerarse siempre como un acto anticonceptivo (un pecado de anticoncepción, desde el punto de vista moral). La cuestión no era, por tanto, si la anticoncepción es pecado o no, sino más bien si el uso conyugal de la "píldora anovulatoria" es o no anticoncepción.

La respuesta de Humanae vitae, en el marco de la doctrina "muchas veces expuesta por el Magisterio de la Iglesia" -y que "está fundada sobre la inseparable conexión que Dios ha querido, y que el hombre no puede romper por propia iniciativa, entre los dos significados del acto conyugal: el significado unitivo y el significado procreador" (HV, n. 12) - es que "cualquier acto matrimonial debe quedar abierto a la vida" (Cfr. HV, n. 11) y, por tanto, que "queda además excluida toda acción que, o en previsión del acto conyugal, o en su realización, o en el desarrollo de sus consecuencias naturales, se proponga, como fin o como medio, hacer imposible la procreación" (HV, n. 14).

Una lectura atenta de los textos citados permite concluir que se dicen cuatro cosas: (a) la sexualidad humana propia del lenguaje con el que los esposos se relacionan en el acto matrimonial tiene dos significados fundamentales: el "significado unitivo" (la unión de amor de los esposos), el "significado procreativo" (la transmisión de la vida humana); (b) en segundo lugar, según "el designio o plan de Dios" "hay una inseparable conexión" entre estos dos significados; en tercer lugar, "el hombre no puede romper por propia iniciativa" esta inseparable conexión; y finalmente, en cuarto lugar, Humanae vitae dice que la inseparable conexión de esos significados se rompe de hecho por la así llamada "píldora". En esa ruptura está, en última instancia, la esencia de la anticoncepción.

En cualquier caso, todas esas afirmaciones dan lugar a la formulación de una norma o principio, que, de alguna manera y desde el punto de vista objetivo, sintetiza la doctrina de Humanae vitae sobre la moralidad del acto conyugal: la inseparabilidad de los significados unitivo y procreador del acto conyugal. Y se debe subrayar que esa inseparabilidad se debe observar en todos y cada uno de los actos conyugales: "cualquier acto matrimonial -son las palabras de la Encíclica antes citadas - debe quedar abierto a la vida" (HV, n. 11).

Llegados a este punto, podemos platearnos algunas preguntas, que $-\mathrm{a}$ mi juicio - pueden ayudarnos a comprender su racionalidad. Entre otras: ¿Por qué es profundamente humana? Con ella están estrechamente relacionadas, que, sin embargo, dado el tiempo de que dispongo no voy aconsiderar: ¿Es una norma que en ningún caso admite excepciones? ¿Cuál es la razón de que el dominio del hombre sobre la corporalidad no pueda interferir en la apertura a la vida del acto conyugal? ¿Existe diferencia moral entre regulación de la natalidad llevada a cabo por métodos naturales y la practicada por medios artificiales? 


\section{Una norma o "principio" profundamente racional y humano}

Cuando se dice que la inseparabilidad de los significados es una norma profundamente racional y humana, se afirman dos cosas. Una -la primeraes que no se trata de una norma o "una doctrina inventada por el hombre. Ha sido inscrita por la mano creadora de Dios en la misma naturaleza humana y ha sido confirmada por Él en la Revelación" (Juan Pablo II, Al II Congreso Internacional de Teología Moral, 12.XI.1988, n. 3, enEF, V, pp. 4922-4993). Y otra— la segunda - , que para descubrir esa fundamentación racional de esa doctrina ("el bien que nos precede"), es necesario que el hombre entre en sí mismo para descubrir las normas fundamentales de la ley moral natural que Dios ha inscrito en su corazón"14.

Es, ciertamente, una norma intrínseca interior, inscrita en nuestra naturaleza humana; pero debe ser consciente e interiorizada. Solo entonces es norma moral. Si se dice que es una norma o ley biológica, ha de entenderse que lo es solo secundariamente y solo en cuanto que pertenece a la naturaleza humana y que, por eso, es una ayuda para descubrir la intención creadora de Dios inscrita en esa naturaleza. Las leyes biológicas son de una naturaleza; pero de una naturaleza humana, de una persona. La persona -también la que vive hoy-puede entender la verdad de esa norma. Expresión de la confianza de Pablo VI en esa capacidad del hombre para descubrir y comprender la verdad de esta doctrina son las palabras recogidas ya en la Encíclica: "Nos pensamos que los hombres, en particular los de nuestro tiempo, se encuentra en grado de comprender el carácter profundamente racional y humano de este principio fundamental" (HV, n. 12).

La inseparabilidad de los dos significados del acto conyugal es una exigencia de su misma estructura y el hombre es capaz de descubrirla con la luz de su razón; pero sólo llega a ser norma práctica de su obrar moral cuando se identifica consciente y libremente con la relectura, en la verdad, del lenguaje de la los significados del acto conyugal. La estructura del acto conyugal -lo que es y está llamado a ser, según su propia naturaleza - no es la norma del recto obrar moral de los esposos en esa recíproca relación; pero si es el fundamento necesario de la verdad de esa relación que los esposos deben descubrir y a la que deben acomodar su actuación. En el sentido ontológico es una norma interior a la persona, porque expresa la verdad y el bien del acto conyugal; y es interior, en el sentido epistemológico, porque está escrita en el corazón

${ }^{14}$ Cfr. Benedicto XVI, Encíclica Caritas in veritate (29.VI.2009), n. 68: "El desarrollo de la persona se degrada cuando ésta pretende ser la única creadora de sí misma. [...] hemos de fortalecer el aprecio por una libertad no arbitraria, sino verdaderamente humanizada por el reconocimiento del bien que la precede. Para alcanzar este objetivo, es necesario que el hombre entre en sí mismo para descubrir las normas fundamentales de la ley moral natural que Dios ha inscrito en su corazón". 
del hombre y de la humanidad. La norma de la inseparabilidad de esos dos significados promulgada por Humanae vitae y enseñada repetidamente por la doctrina de la Iglesia, deriva de la Ley de Dios.

El Papa, movido por el deber y las exigencias de la caridad pastoral, propios de su Oficio Apostólico, recuerda de nuevo la norma. Pero, en el fondo, - desde el punto de vista racional — es solo la confirmación de lo que la razón humana es capaz de descubrir como propio de las estructuras de la vida, del amor y de la dignidad humana. Viene a ser una formulación más precisa del respeto a las leyes de la naturaleza que procede de la Sabiduría Creadora de Dios. Como recordaría veinte años más tarde Juan Pablo II, con palabras de Pablo VI:

Hemos estudiado, leído, discutido cuanto pudimos y también hemos orado mucho. Invocando las luces del Espíritu Santo hemos puesto nuestra conciencia en la plena y libre disponibilidad a la voz de la verdad, tratando de interpretar la norma divina que vemos brotar de la intrínseca exigencia del auténtico amor humano, de las estructuras esenciales de la institución matrimonial, de la dignidad personal de los esposos,de su misión al servicio de la vida, como también de la santidad del matrimonio cristiano (Juan Pablo II, A los representantes de las Conferencias Episcopales (7.XI.1988, n. 2), en EF, V, pp. 4905-4906; cfr. Pablo VI, Audiencia general (31.VII.1968), nn. 3 y 6, en EF, III, pp. 1942-1945).

La dificultad de la norma de esa inseparabilidad, tanto por parte de los esposos como por aquellos que pueden y deben ayudarles, puede venir, no de la falta de capacidad para leer la norma "escrita ya en su corazón", sino de la concupiscencia, que, ocupando ese corazón arrastre a su voluntad en una dirección que realice la verdad. Hablar, por tanto, de "conflicto de valores o de bienes" y, como consecuencia, preferir unos y rechazar otros no es moralmente correcto, contradice abiertamente la verdad que defiende y protege la norma moral.

Es una norma profundamente racional y humana, inscrita en la naturaleza humana, contenida también en Revelación ${ }^{15}$. Ciertamente, como hace observar Juan Pablo II,

aunque la norma moral, formulada así en la Encíclica Humanae vitae, no se halla literalmente en la Sagrada Escritura, sin embargo, por el hecho de estar contenida en la Tradición y -como escribe el Papa Pablo VI- haber sido «otras muchas veces expuesta por el Magisterio» $(\mathrm{HV}, 12)$ a los fieles, resulta que esta norma cor-

15 Juan Pablo II dedica varias de sus Catequesis a tratar de la fundamentación bíblica de la Encíclica: las comprendidas entre el 11.VII.1984 y el 5.IX.1984; también las que van del 3.X.1984 al 21.XI.1984. 
responde al conjunto de la doctrina revelada contenida en las fuentes bíblicas (cfr. HV, 4) (Juan Pablo II, Audiencia general (18.VII.1984), n. 3, en EF, V, p. 4146).

Y si pertenece al orden revelado por Dios, son claras, entre otras cosas, que el Magisterio de la Iglesia no invade ningún campo ajeno a la competencia que es propia; y también, que el valor vinculante de esa norma procede de la autoridad que, como Magisterio de la Iglesia, tiene sobre el orden moral revelado.

\section{Autoridad o valor vinculante}

Al hablar de Humanae vitae como "signo de contradicción" señalábamos que las reacciones desfavorablesa la Encíclica se habían debido sobre todo, segúnargumentaban los que justificaban el "disenso", a dos motivos. Uno era que, como la doctrina no se proponía infalible, podía ser reformada (algunos incluso decían que "debía ser reformada"; Cfr. VV.AA., "Humanae vitae": 20 anni dopo, Ares, Milano 1989, p. 1029). El otromotivo era que la norma que de la inseparabilidad de los dos dignificados del acto conyugal pertenece al orden de la razón humana y, por tanto, el valor vinculante de la norma dependerá de la fuerza de los argumentos racionales que se aducían. La cuestión de fondo, presente en uno y otro motivo, está en el modo de interpretar la autoridad y competencia del Magisterio de la Iglesia en las cuestiones de moral natural. En el caso de Humanae vitae, era la autoridad dela Encíclica al tratar de la regulación de la natalidad y de algunos problemas anejos. ¿Cuál es la naturaleza de ese Magisterio? ¿Es una limitación o negación del papel de la "razón”, de la libertad de la conciencia?

Si se parte de que el Magisterio, aunque puede pronunciarse sobre cuestiones morales en el ámbito humano, la autoridad y el carácter vinculante de sus pronunciamientos se debe a la fuerza o al valor probativo de su argumentación, se defenderá que lo "razonable" será el disenso (cuando no rechazo) en el caso de que los argumentos aducidos no convenzan o se piense que son más fuertes los que se presentan en contra ${ }^{16}$. Muy relacionada con esta posición es también la de quienes afirman que el Magisterio solo es competente y cuenta con la asistencia del Espíritu Santo cuando interviene sobre los contenidos de la Revelación; y que, por eso, en las intervenciones del Magisterio en los temas de moral, es necesario hacer una distinción clara entre el Evangelio de Cristo y la forma cultural con que ese Evangelio ha llegado hasta nosotros. El mensaje del Evangelio, válido para todos los tiempos y lugares -se dice-, es necesariamente de tipo general y exhortativo, en el que no caben normas

\footnotetext{
${ }^{16}$ En las notas 17 a 21 se da ya noticia de algunos autores alineados en esta posición.
} 
ni prohibiciones específicas (Cfr. Böckle 1981, p. 84; Schillebeecks 1983, p. 238). Por lo que, como Humanae vitae trata cuestiones de moral humana, esa doctrina no es infalible de la que no se pueda disentir (Cfr. Böckle 1968, pp. 20-22; Curran 1976, p. 312; Sporken 1969). Y si la autoridad del Magisterio no llega a las determinaciones concretas o parece que no es convincente en un caso determinado ¿cómo puede considerarse que vincula la libertad de la conciencia? (Cfr. Häring 1981c, p. 234; Häring 1970).

En el caso que nos ocupa -la naturaleza y valor vinculante de la norma de Humanae vitae - es necesario advertir, como ya decía Juan XXIII, que "una cosa es la sustancia del depositum fidei, es decir, de las verdades que contiene nuestra venerada doctrina, y otra, la manera como se expresa. Esto es lo que ha de tenerse en cuenta, con paciencia, si fuera necesario, ateniéndose a las normas y exigencias de un magisterio de carácter prevalentemente pastoral" ${ }^{17}$. Además de la referencia a la naturaleza y características propias del magisterio pastoral (que no voy a considerar), el texto distingue entre lo que es la sustancia, es decir, lo que entendemos como contenidos de la revelación, y la formulación o expresión que puede hacerse de ese depósito o contenido. Se sostiene por todos que la Iglesia, como parte de la misión que le ha sido confiada por Cristo, está revestida de autoridad infalible en relación con la sustancia del depositum, de tal manera que los pronunciamientos que hace en ese campo son definitivos e irreformables; también es competente y goza de la misma autoridad en todo aquello que es necesario para la expresión y formulación adecuada de ese depositum, si bien, con el paso del tiempo, son posibles otras formulaciones, aunque siempre en el mismo sentido y dirección. Según lo recuerda el Concilio Vaticano II, la autoridad el Magisterio de la Iglesia "se extiende tanto cuanto abarca el depósito de la revelación, que debe ser custodiado santamente y expresado con fidelidad" (LG, n. 25).

La teología, en un intento de explicar el alcance de esa competencia o autoridad se ha servido de la distinción entre "objeto primario" y "objeto secundario". El primero

incluye los contenidos de la revelación cristiana, es decir, lo que ha sido directamente revelado y está formalmente contenido en el depósito de la fe. El objeto secundario se refiere a lo que, no habiendo sido directamente revelado, está sin embargo vinculado necesariamente al depósito de la revelación en virtud de una ligazón tan profunda que, si el magisterio no fuera también competente en ese terreno, le sería imposible conservarlo íntegramente, explicarlo adecuadamente o defenderlo de manera eficaz de los ataques externos" (Ardusso 1998, pp. 272-273).

${ }^{17}$ Juan XXIII, En la apertura del Concilio Vaticano II (11.X.1962). Parecidas afirmaciones se encuentran en GS, n. 62. 
No existe discordancia sobre la competencia del Magisterio respecto de lo que se acaba de describir como objeto primario. Tampoco en relación con el objeto secundario, al menos cuando éste se entiende en un sentido muy restringido $^{18}$. Se afirma además que, en uno y otro caso, el Magisterio goza de infalibilidad y conlleva, por parte de los fieles, la adhesión irrevocable de la $\mathrm{fe}^{19}$.

En relación con el tema de esta ponencia, el problema se presenta cuando se trata de determinar si las normas morales "categoriales", accesibles de suyo a la luz de la razón, forman parte del contenido de la Revelación, o, en el caso de que no sean reveladas, si su enseñanza es necesaria para exponer adecuadamente la Revelación. Con otras palabras: ¿la autoridad del Magisterio de la Iglesia alcanza también a las normas morales concretas? Según señala la Instrucción Donum veritatis (sobre la vocación eclesial del teólogo), son diversos los modos que pueden revestir las intervenciones del Magisterio: (a) pronunciamientos infalibles sobre verdades reveladas de fe y costumbres; (b) pronunciamientos infalibles sobre verdades de fe y costumbres que, aunque no están directamente reveladas, están estrechamente vinculadas con las que son directamente reveladas; (c) pronunciamientos no infalibles sobre cuestiones de fe y costumbres; (d) pronunciamientos en materias de por sí no irreformables, es decir, sobre asuntos discutibles en los que se encuentran implicados, junto a principios seguros, elementos conjeturales y contingentes (Cfr. Congregación para la Doctina de la Fe, Instr. Donum Veritatis [24.V.1990], n. 24).

Por eso el mismo documento advierte que, para una valoración adecuada, será necesario

tener en cuenta el carácter propio de cada una de las intervenciones del Magisterio y la medida en que está implicada su autoridad; pero también el hecho de que todas ellas derivan de la misma fuente, es decir, de Cristo, que quiere que su pueblo camine en la verdad plena. Por este mismo motivo las decisiones magisteriales en materia de disciplina, aunque no estén garantizadas por el carisma de la infalibilidad, no están desprovistas de la asistencia divina, y requieren la adhesión de los fieles (Ibídem, n. 17).

Como hace notar el Joseph Ratzinger, en relación con el asentimiento que se debe prestar al así llamado "magisterio auténtico no infalible"es necesario

${ }^{18}$ Este es también el sentido del Catecismo de la Iglesia Católica, n. 88: "El Magisterio de la Iglesia ejerce plenamente la autoridad que tiene de Cristo cuando define dogmas, es decir, cuando propone, de una forma que obliga al pueblo cristiano a una adhesión irrevocable de fe, verdades contenidas en la Revelación divina o también cuando propone de manera definitiva verdades que tienen con ellas un vínculo necesario" (En adelante: CEC).

${ }^{19}$ Algunos autores, sin embargo, sostienen que "las decisiones magisteriales infalibles sólo son posibles si su objeto está revelado”. Así piensan, p. e., Gutwenge 1970, p. 520; Sullivan 1996, pp. 24-27. 
evitar "una reducción en clave legalista de la noción de fe", que llevaría a reconocer la autoridad del Magisterio allí sólo donde está en juego la infalibilidad. "El hecho de que el Magisterio, en determinadas condiciones goce del carisma de la infalibilidad 'sólo tiene realmente sentido si esta circunscripción y delimitación, necesaria en un caso particular, se inscribe dentro de la totalidad viva de la certeza común de la fe. Por eso más importante que la noción de infalibilidad es la de auctoritas" (J. Ratzinger, La Teologia e il magistero della Chiesa, 99 [citado en: Ardusso 1998, p. 168]). Es cierto que la autoridad del Magisterio de la Iglesia tiene distintos grados. Pero - continúa Ratzinger - "el que un grado no sea igual a otro no significa sin embargo que la autoridad considerada menor no sea en modo alguno auctoritas [...] y pueda considerarse como una hipótesis" (Ibídem, p. 200).

La luz del Magisterio de la Iglesia en el terreno de la moral natural no se sitúa (como otra más) al lado de la que el hombre ya tiene sobre esa materia a partir de la actividad racional. Cierto que, como ya se ha dicho, entre sus finalidades está la de llevar a plenitud esa capacidad; se trata de una luz que, elevando las posibilidades naturales de la razón, consigue paralelamente que éstas sean sanada y perfeccionadas en cuanto tales. Pero es una luz de orden superior. La fuerza de la autoridad del Magisterio no depende de los resultados de la investigación, sino de la autoridad del Señor ${ }^{20}$. Es la autoridad del mismo Cristo la que actúa en el Magisterio. La Iglesia habla en nombre de Dios. Tiene una visión original e integral del hombre que deriva de su conocimiento de Cristo, el hombre nuevo. Por eso la luz que la Iglesia ofrece sobre el orden moral natural ha de guiar siempre las conductas. Es una luz que se impone como obligación, ya que, por un lado, tan sólo en Cristo es posible la realización plena del hombre; y, por otro, sólo en la fidelidad al Magisterio hay garantía de que se vive con autenticidad el seguimiento de Cristo. La consecuencia es que ningún fiel puede vivir su vida en Cristo contra las normas morales enseñadas por el Magisterio o, sin hacer referencia a él, ignorándolo.

La fidelidad al Magisterio es una garantía de la fidelidad a la verdad en el seguimiento de Cristo, porque, si bien es verdad que la conciencia es una instancia ética de tal manera inviolable, que nadie puede ser obligado a actuar en su contra y que nadie puede ser violentado y obligado por la fuerza a aceptar la verdad, también lo es que esa inviolabilidad no se puede interpretar como si la persona fuera libre para negar la verdad o que no se considerara culpable si no reconociera la verdad. No se puede interpretar en el sentido de que ella, por sí misma, fuera la creadora de la norma moral. Existe una verdad y un bien que le precede.

${ }^{20}$ Entre los textos del Magisterio que se refieren a este punto, pueden recordarse a Dei Verbum, n. 10 y HV, n. 28. 
"En lo más profundo de su conciencia -recuerda el Concilio- descubre el hombre la existencia de una ley, que él no se dicta a sí mismo, pero a la cual debe obedecer [...] Porque el hombre tiene una ley escrita por Dios en su corazón, en cuya obediencia consiste la dignidad humana y por la cual será juzgado personalmente" (GS, n. 16). Y precisamente ahí, en ser el espacio que sirve y hace posible oír y obedecer la "voz de Dios", radica la dignidad de la conciencia y, como acaba de decirse con palabras del Concilio, la dignidad de la persona humana. Pero esa voz la oye y a esa voz responde una persona condicionada por unas concretas y particulares cualidades morales, $\mathrm{y}$, además, en espacio y tiempo determinados. Estos y otros condicionantes, que también darse, pueden hacer no solo que la persona encuentre de hecho dificultad en descubrir con claridad la voz de Dios y que, incluso, caiga en el error en la escucha de esa voz. La experiencia muestra suficientemente que "no rara vez ocurre que yerra la conciencia por ignorancia invencible, sin que ello suponga la pérdida de su dignidad" (Cfr. GS, n. 16).

No cabe, por eso, hablar de una oposición entre el Magisterio de la Iglesia, la ley moral y la conciencia. Y no es posible porque, en el sentido en que se habla aquí de la ley moral, esta no es otra cosa que la expresión de una verdad inscrita en el interior del corazón humano, no solo la expresión de una verdad interiorizada. Es una verdad interior en el sentido ontológico, porque es expresión de la verdad sobre el bien del hombre, y es también verdad interior en el sentido epistemológico, porque está escrita en el corazón del hombre, en la conciencia moral de la humanidad (Cfr. Juan Pablo II, Carta a los Jóvenes [31.III.1985], n. 6; cfr. del Portillo 1989, pp. 31-38). Pero, por eso mismo, tampoco es posible hablar del Magisterio de la Iglesia como de una instancia que limita o contraría la dignidad y libertad de la conciencia. Y no cabe esa contraposición, porque en ese espacio - en el que resuena y se responde a la voz de Dios y el que "se siente a solas con Dios" (GS, n. 16), no está "a solas consigo misma". De las decisiones que tome en ese encuentro, ella -y solo ella - es la responsable verdadera. Nadie le puede sustituir. A la vez, sin embargo, dispone siempre de la "compañía" y ayuda de Dios -luz para conocer y fuerza para querer y vivir- para seguir libremente la dirección y el camino del bien y de la verdad. Una ayuda, que, cuando se trata de la conciencia cristiana, reviste las características de la luz nueva del Espíritu Santo capaz, entre otras cosas, de llevar a plenitud el conocimiento de las verdades del orden moral natural. A cuyo servicio -según acaba de verse en el apartado anterior- está la actuación del Magisterio de la Iglesia.

Se comprende, por eso, la tragedia que supone, para la persona, romper el vínculo de la conciencia con la fuente de esa dignidad. A solas consigo misma y convertida en la norma última de la moralidad - es decir, la que decide en última instancia sobre la verdad del bien y mal moral - la conciencia pierde esa dignidad y ya no tiene más inviolabilidad que le puedan ofrecer sus pro- 
pios caprichos, las modas del momento, etc. Es el resultado al que conduce el camino que se recorre "cuando el hombre se despreocupa de buscar la verdad y el bien y la conciencia se va progresivamente entenebreciendo por el hábito del pecado" (Cfr. GS, n. 16).

En la contraposición que se pretende ver entre el Magisterio y la conciencia (entre la ley moral cuya custodia y transmisión autorizada corresponde al Magisterio y la libertad de la conciencia), lo que hay detrás, en última instancia, es una concepción errónea de la relación entre la conciencia y el ser, según la cual se considera a la conciencia el garante último de la libertad" (Ratzinger 1985, p. 12). En el fondo, hay un no reconocimiento de la creación como fruto de la Sabiduría divina Creadora: no reconocer a Dios Creador como la única y definitiva fuente del orden moral en el mundo. Y, en cambio, en dar al hombre la misión -como imagen de Dios- de dirigir el orden mundano.

\section{Tercera Parte. Una visión global del hombrey de su vocación}

Advertir el carácter profundamente racional y humano de la Encíclica exige ser conscientes de la naturaleza y dignidad del ser humano. La persona humana no viene a la existencia como fruto del acaso o de la necesidad. En el origen de cada persona hay un acto creador de Dios. Se dice, por eso, que los esposos son "cooperadores" con Dios en el origen de la vida. En el acto procreativo los esposos ofrecen el espacio en el que, mediante esa cierta cooperación, Dios crea la vida humana (Cfr. GS, n. 50).

La relación de los esposos a través del lenguaje de la sexualidad, propio de la unión conyugal, no es algo puramente biológico. Es un acto que va de persona a persona $\mathrm{y}$, como tal, es decir, como acto de personas que se entregan a través de ese lenguaje, ni los esposos ni tampoco otros -poderes públicos o personas particulares - pueden excluir de la persona nada de lo que la constituye en toda su integridad.

Lo que está en juego en el acto procreativo es, en primer lugar, la verdad de la creación -El principio de la Creación, es decir: que Dios es el "creador del cielo y de la tierra", de todo cuanto existe-. Es lo que se considera en el primer apartado. Y en segundo lugar lo que está detrás esla verdad y dignidad del hombre: ¿con qué "idea" de hombre ha de ser coherente el acto procreativo para que la entrega de lapersona a través del lenguaje de la sexualidad responda a la verdad? Es lo que se contempla el apartado segundo -La persona humana, una totalidad unificada-. 


\section{El principio de la Creación}

Insistimos de nuevo en que Humanae vitae, si bien a primera vista aborda el tema particular de la contracepción, la respuesta que da se enmarca en el plano más profundo: el de la relación del hombre con el Dios Creador. Así lo pone de manifiesto la casi generalidad de las publicaciones sobre la Encíclica. Se trata, por tanto, de valorar el significado del origen del ser humano como fruto de un acto del amor creador de Dios y, por tanto, llamado a responder a este acto de amor. (Solo así se reconoce la total y radical dependencia del acto mismo de ser).

La comprensión o no comprensión de esta verdad y realidad fundamental está en la raíz del rechazo o aceptación de la Humanae vitae. "Esta es -se ha escrito- la verdadera causa de los debates yreacciones sobre esta Encíclica" (Caffarra 1989, p. 184). Porque no es posible que se dé en el ser humano momento alguno (uno de ellos es la concepción) en que no tenga lugar esa dependencia radical. Por eso se habla de cooperación por parte de los esposos en la procreación. La libertad de los padres puede hacer que se respete o se rechace ese significado. Pero el acto conyugal no es un hecho puramente biológico, sitúa a los esposos en una relación real con el acto creador de Dios (Cfr. Finnis 1980, p. 633).

No parece exagerado, por eso, afirmar que la negación de ese reconocimiento de la actuar divino en el hecho de la fertilidad - lo que tiene lugar cuando no se observa la inseparable conexión de los significados unitivo y procreador del acto conyugal — responde a una mentalidad anti-teísta. Se rechaza el reconocimiento de la soberanía del Creador, que es sustituida por la creatura, cuya condición se niega, por eso, a la vez. Y cuando esto ocurre viene necesariamente la negación de la verdad del hombre.

Como bien se sabe, el lugar privilegiado de la relación de la persona con Dios es la conciencia moral. Es ahí donde la persona humana se encuentra a solas con Dios. De tal manera es así que, en ese encuentro, nadie puede ser sustituido: ni en la escucha de la voz de Dios que resuena en el interior ni en la respuesta que cada uno debe dar a esa voz. De ahí, entre otras cosas, que negar la existencia de normas morales absolutas o que haya actos intrínsecamente malos -siempre y por encima de cualquier circunstancia - es dejar a la conciencia sola consigo misma. Y por eso mismo es hacer, de la conciencia, la norma última de la moralidad, es decir, la que decide en última instancia del bien o mal moral. Desde esa perspectiva, lo que la Iglesia, en el ejercicio de su Magisterio, puede decir no solo estorba, sino que impide lo que se interpreta como "creatividad". En el fondo, hay un no reconocimiento de la creación como fruto de la Sabiduría divina Creadora: no reconocer a Dios Creador como la única y definitiva fuente del orden moral en el mundo. 
Y, en cambio, en dar al hombre la misión -como imagen de Dios- de dirigir el orden mundano. Lo que hay detrás, en última instancia, es una concepción errónea de la relación entre la conciencia y el ser, según la cual se considera a la conciencia el garante último de la libertad (Cfr. Ratzinger 1985, p. 12; Melina 1993, p. 87).

La negación (más o menos explícita) de este principio -Dios como creador de todo - ha desembocado en la difusión de una mentalidad según la cual el obrar intramundano del ser humano no tiene, por sí mismo, un significado decisivo en la relación del hombre con Dios Creador. De esta misma raíz deriva también la distinción entre el plano "categorial" y el "trascendental" que relega al nivel solo intencional los preceptos morales; la moral de la "opción fundamental” (B. Häring, E. Chiavacci, F. Böckle, J. Fuchs, T. Goffi, M. Vidal); la distinción entre ethos mundano y ethos de la Salvación, con el debate subsiguiente acerca del proprium de la moral cristiana (A. Auer). Las consecuencias son evidentes en el campo de la sexualidad y, de manera muy particular, cuanto se relaciona con el amor y acto conyugal.

\section{La persona humana, una totalidad unificada ("corpore et anima unus")}

Humanae vitae no representa ninguna revolución respecto de la doctrina anterior sobre el hombre. Sustancialmente Pablo VI propone de nuevo la visión antropológica y moral que Pío XI, en su encíclica sobre el matrimonio, había considerado como doctrina cristiana enseñada desde los orígenes y nunca modificada (Cfr. Pío XI, Encíclica Casti connubii [31.XII.1930], n. 4, en EF, I, p. 712).

La respuesta de la doctrina de Humanae vitae -recordamos- si bien responde a una pregunta muy concreta -la de la licitud o ilicitud de los contraceptivos químicos - rebasa los límites de esa pregunta y encierra una gran riqueza doctrinal, particularmente antropológica. La inseparabilidad de los aspectos unitivo y procreador del acto conyugal -uno de los principios fundamentales para la comprensión normativa de la Encíclica y que lleva a comprender el acto conyugal en sus diversas dimensiones (la biológica y la espiritual) de una manera unitaria - responde a una visión antropológica de la persona humana como "totalidad unificada".

El hombre - es un dato de experiencia - se advierte a sí mismo como una realidad una y compleja. Aun cuando es consciente de la pluralidad y diversidad de operaciones cada ser humano percibe a la vez que su "yo" es el mismo y único. "El mismo e idéntico hombre es el que percibe, entiende y siente" (Cfr. Tomás de Aquino, Summa theologiae, I, q. 76, a. 1). No existen principios diferentes para cada una de las actividades que realiza. 
La unidad del cuerpo y el alma es tan profunda que se debe considerar al alma como 'forma' del cuerpo ( $\mathrm{cf}$ Cc de Vienne, a. 1312, DS 902): es decir, gracias al alma espiritual, la materia que integra el cuerpo es un cuerpo humano y viviente; en el hombre, el espíritu y la materia no son dos naturalezas unidas, sino que su unión constituye una única naturaleza (CEC, n. 365).

El ser humano debe su ser persona a su espíritu, pero de ello no se sigue que la persona sea un ser espiritual que tiene cuerpo. Lo que llamamos persona la "totalidad unificada" que es el hombre. El cuerpo y el espíritu (en la persona humana) o son dos realidades que existen con anterioridad a su composición. El espíritu es creado para informar al cuerpo; el cuerpo está intrínsecamente orientado a su unión con el espíritu (sólo es humano en cuanto informado por el espíritu).

En la complejidad del ser humano existen elementos diversos, físicos y espirituales, que hacen posible distinguir la composición materia-espíritu - cuerpoalma; pero esa composición no se puede explicar como si el cuerpo y el alma fueran dos realidades puesta la una en o al lado de la otra. El cuerpo y el alma son dos principios constitutivos de la misma y única persona. El hombre es persona gracias al alma: en el alma está la razón de la subsistencia de la persona. Y como el alma es única, hace "no sólo que el hombre sea hombre, sino también animal y viviente y cuerpo y sustancia y ente" (Cfr. Tomás de Aquino, De spiritu creaturarum, 3). "El alma racional da al cuerpo humano todo lo que el alma sensible da a los animales y algo más" (Tomás de Aquino, Summa theologiae, I, q. 76, a. 2 as 2). Este algo más es la perfección de orden superior, espiritual, propia de la persona humana, gracias a la cual el hombre está dotado de una interioridad que le hace posible entrar en comunicación con las demás personas y principalmente con Dios. Trasciende el simple ser individuo de una especie y está en sí mismo lleno de sentido. El cuerpo -esa es la consecuencia -es la persona en su visibilidad. Señalar el cuerpo humano es señalar a la persona. Imaginar la posibilidad de relacionarse con el cuerpo humano, y no con la persona, es imposible ${ }^{21}$.

En esa unidad, los dos coprincipios - el espíritu y el cuerpo - no pierden su propia naturaleza, siguen siendo dos realidades esencialmente distintas, hay una distinción esencial entre los diversos dinamismos: los espirituales, los físicos, etc. La unidad se da en el nivel del "ser". Es uno el "yo" que realiza las

${ }^{21}$ A este propósito se debe tener presente que, como señala Juan Pablo II en Carta a las familias, Gratissimam sane (2.II.1994) n. 19: «La fuente más rica para el conocimiento del cuerpo es el Verbo hecho carne. Cristo revela el hombre al hombre (cf GS 22). Esta afirmación del Concilio Vaticano II es, en cierto modo, la respuesta, esperada desde hacía mucho tiempo, que la Iglesia ha dado al racionalismo moderno» (En adelante: $\mathrm{GrS})$. 
diversas operaciones espirituales, materiales, etc. (Cfr. Marcel 1968, pp. 25-226). Pero

por desgracia el pensamiento occidental, con el desarrollo del racionalismo moderno, se ha ido alejando de esta enseñanza. El filósofo que ha formulado el principio 'cogito, ergo sum': 'pienso, luego existo', ha marcado también la moderna concepción del hombre con el carácter dualista que la distingue. Es propio del racionalismo contraponer de modo radical en el hombre el espíritu al cuerpo y el cuerpo al espíritu. En cambio, el hombre es persona en la unidad del cuerpo y espíritu (GrS, n. 19).

Ni la dimensión biológica es exclusivamente biológica, ni la espiritual es exclusivamente espiritual. Las dimensiones corporales son constitutivas de la naturaleza de la persona humana, de un modo tal que no es posible establecer una separación entre lo corporal y lo espiritual, entre las funciones del cuerpo (que sería la naturaleza) y el espíritu (que sería la persona). Una consideración de la persona que no tuviera en cuenta esa "totalidad" comportaría necesariamente referirse a la sexualidad como pura materia, mera función biológica, una mercancía de consumo: y sin diferencia alguna con la sexualidad animal. Y, por eso, ya no sería posible acceder a la verdad y significado del lenguaje de la sexualidad. En la procreación, por ejemplo, el lenguaje de la sexualidad comportaría la reducción de ese lenguaje a los mecanismos bioquímicos de una reproducción.

No respetar la naturaleza del lenguaje de la sexualidad como expresión de la verdad de la totalidad de la persona sexualidad contribuye al oscurecimiento y desnaturalización de la persona humana: (a) por la separación de la sexualidad de la procreación; y (b) por la separación de la procreación de la sexualidad. El primer paso desemboca en la consideración del cuerpo como una realidad puramente biológica, de la que se puede usar según los fines que se busquen. "La separación entre la sexualidad y la procreación comporta como consecuencia que la sexualidad no se considere como una característica y orientación de la persona humana. [...] La sexualidad no influya ya en la antropología: ha pasado a ser una función que cambia según los gustos" (Ratzinger 1986, p. 17). El segundo lleva a la sustitución de la procreación por los procedimientos técnicos. Y entonces la razón "técnica" ocupa el lugar de la razón "ética" y la facultad procreativa pasa a ser considerada como perteneciente al orden del "hacer" y no del "obrar".

Se comprende, por eso, la importancia de partir de una antropología que, teniendo en su raíz la comprensión de la unidad de la persona como "totalidad", sea capaz de dar razón de la identidad y unidad del sujeto -el yo que actúa- y a la vez, salvaguardando la distinción esencial de los diversos dinamis- 
mos operativos: los espirituales, los psíquicos, los físicos- dé razón también de la pluralidad y diversidad de operaciones que realiza. Como dimensión de la persona, la sexualidad es, en sí, una realidad compleja y afecta a la persona en su núcleo más íntimo «Caracteriza al hombre y a la mujer no sólo en el plano físico, sino también en el psicológico y espiritual con su huella consiguiente en todas sus manifestaciones» (FC, n. 11). Por lo que si, como consecuencia, la fertilidad del acto conyugal no es un hecho puramente biológico, los esposos - tampoco otros: poderes públicos o personas particulares - no podrán excluir de la persona nada de lo que la constituye en toda su integridad. Y no podrán, porque, como acto de personas que se entregan a través del lenguaje de la sexualidad, nada que sea de la persona podrá ser excluido de esa entrega o donación. La valoración adecuada de la sexualidad deberá tener en cuenta la diversidad y complejidad de significados y, por tanto, evitar el grave riesgo de parcelación, es decir, afirmar la verdad y significados de la sexualidad tan sólo a partir de uno o algunos de esos aspectos o niveles.

\title{
HUMANAE VITAE: THE ENCYCLICAL PROPHETIC
}

\begin{abstract}
Fifty years that went by since the promulgation of Humanae vitae underline its prophetic importance and meaning. The rejection of the encyclical was associated -as already denounced by Paul VI $(\mathrm{HV}, 17)$ - with the loss of truth concerning human love and life, the negation of human person, and the domination of the powerful over the weak.

This article reflects on some aspects that render this encyclical prophetic and offers several indispensable keys for its reading, namely, an adequate anthropological vision and a correct interpretation of the Magisterium's competence in the Church with regard to issues concerning natural morality.
\end{abstract}

\section{Resumen}

Los 50 años transcurridos desde la publicación de Humanae vitae ponen de relieve su significado profético y su actualidad. El rechazo de la Encíclica está relacionado -como ya denunciaba Pablo VI (HV, 17)- con la pérdida de la verdad del amor y de la vida humanos, con la negación de la persona y con el dominio de los poderosos sobre los débiles.

El artículo reflexiona sobre algunos de los aspectos que dan razón de esa calificación como profética y ofrece algunas claves necesarias para la lectura de la Encíclica: 
la adecuada visión antropológica y la correcta interpretación de la competencia del Magisterio de la Iglesia en los temas de moral natural.

\begin{abstract}
Abstrakt
Pięćdziesiąt lat, które upłynęły od momentu opublikowania encykliki Humanae vitae, podkreśla jej profetyczną treść i znaczenie. Odrzucenie encykliki było związane - co potępił już Paweł VI w Humanae vitae, n. 17 - z utratą prawdy dotyczącej ludzkiej miłości i życia, negacją osoby ludzkiej i dominacją silnych nad słabymi.

Niniejszy artykuł poświęcony jest niektórym aspektom, które sprawiają, że encyklika ta jest profetyczna, i wskazuje kilka niezbędnych kluczy do jej odczytania, mianowicie, odpowiednią wizję antropologiczną i właściwą interpretację kompetencji Magisterium Kościoła dotyczących naturalnej moralności.
\end{abstract}

Keywords: human love; contraception; conscience; Magisterium; morality

Palabras clave: Amor humano; Contracepción; Conciencia; Magisterio; Moral

Słowa kluczowe: miłość ludzka; antykoncepcja; sumienie; Magisterium; moralność

\title{
BIBLIOGRAFÍA
}

Alburquerque E. (2004), Matrimonio y familia: teología y praxis cristiana, Madrid.

Alonso E. (2014), La recepción de la encíclica «Humanae vitae» en el ámbito católico de los Países Bajos, "Excerpta e Dissertationibus in Sacra Theologia", 62, 317-398.

Angelia O. (2009), The reception of enciclical «Humanae vitae» in the United States, "Excerpta e Dissertationibus in Sacra Theologia”, 53, 421-492.

Ardusso F. (1998), Magisterio eclesial, Madrid.

Auer A. (1984), Autonome Moral und christlicherr Glaube, Düsseldorf.

Böckle F. (1965), La regulación de los nacimientos: discusión del problema dentro de la Iglesia, "Concilium" 5, 101-129.

Böckle F. (1981), I concetti fondamentali della morale, Brescia.

Böckle F. (1968), Freiheit und Bindung. Dokumente zur Enzyklika Humanae vitae, Kevelaer.

Caffarra C. (1983), La trasmissione della vita nella «Familiaris consortio», "Medicina e morale" 5, 395.

Caffarra C. (1988), La competenza del Magistero nell'insegnamento di norme morali determinate, "Anthropotes" 4, 15.

Caffarra C. (1989), «Humanae vitae»: venti anni dopo, en: AA.VV., «Humanae vitae»: 20 anni dopo, Milano, 183-195.

Curran Ch.E. (1976), Il pluralismo nella teologia morale cattolica, "Rivista di teología morale" 30, 311-332.

Del Portillo Á. (1989), Coscienza morale e Magistero, en: AA.VV., «Humanae vitae»: 20 anni dopo, Milano: Ares, 31-38.

Elizari F.J. (1981), Técnicas de reproducción asistida, en: López Azpitarte, E. y otros, Praxis cristiana, II, Madrid, 221-234. 
Felici P. (1986), De la «Gaudium est spes» a la «Humanae vitae», "L'Osservatore Romano" (10-X1968), 1-25.

Finnis J. (1980), «... Objectivis criterios ex personae eiusdemque actuum desumptis...», en: Ética y Teología ante la crisis contemporánea, Pamplona, 633-642.

Fuchs J. (1970), Esiste una moral cristiana?, Roma-Brescia.

Fuchs J. (1978), Responsabilità personale e norma morale, Bologna.

Gutwenge E. (1970), ¿Qué papel desempeña el magisterio en la fe de la comunidad eclesial?, "Concilium" 51, 42-57.

Hamel E. (1969), Conferentiae Episcopales et Encyclica «Humanae vitae», "Periodica de re morali canonica liturgica" 58, 243-349.

Häring B. (1969), The inseparability of the unitive-procreative. Functions of the Marital Act, en: Contraception: Authority and Dissent, ed. Ch. Curran, New York: Herder and Herder, 183-185.

Häring B. (1981), Pastorale Erwägungen zur Bischofssynode über die Ehe und Familie, "Theologie der Gegenwart" 24, 71-80.

Häring B. (1981), Libertad y fidelidad en Cristo, Barcelona.

Häring B. (1981), The Synod, The Synod of Bishops on the family, "Studia Moralia" 19, 231-257.

Häring B. (1970), La crisis de la «Humanae vitae», Bilbao.

Juza L. (2010), La recepción de la encíclica Humanae vitae en las revistas teológicas del ámbito alemán, en: Universidad de Navarra, Excerpta e Dissertationibus in Sacra Theologia, 56, Pamplona, $157-252$.

Komonchak J.A. (1978), «Humanae vitae» and its reception: Ecclesiological reflections, "Theological Studies" 39, 221-257.

López Azpitarte E. (1981), La regulación de los nacimientos, en: López Azpitarte, E. y otros, Praxis cristiana, II, Opción por la vida y el amor, Madrid, 425-458.

Marcel G. (1968), Etre et avoir, Paris.

Melina L. (1993), Morale: tra crisi \& rinovamento. Gli assoluti morali, l'opzione fondamentale, la formazione della coscienza, Milano.

Moltmann J. (1972), Uomo. L'antropologia cristiana tra i conflitti, Brescia.

Ocáriz F. (1988), La nota teologica dell'insegnamento dell'Humanae vitae sulla contraccezione, "Anthropotes" 4, 25-43.

Ocáriz F. (1989), La competenza del Magistero della Chiesa in «moribus», en: AA.VV., «Humanae vitae»: 20 anni dopo, Milano, 125-138.

Paupert J.M. (1967), Contrôle des naissances et théologie. Le dossier de Rome, Paris.

Rahner K. (1976), Basic observations on the Subjet of the Changeable and Unchangeable Factors in the Church, "Theological Investigations" 14, 15.

Ratzinger J. (1985), Le fonti della teologia morale, "CRIS-Documenti" 54, 12.

Ratzinger J. (2008), La encíclica «Humanae vitae», signo de contradicción, "L'Osservatore Romano" (25-VII-2008).

Ratzinger J. (1986), Panorama de la théologie morale dans le monde, "Rivista di teologia morale" 69, 13-18.

Ratzinger J. (1987), Magistero della Chiesa e Teologia Morale, en: AA.VV., Persona, Veritá e morale, Roma, 19-23.

Schillebeecks E. (1983), Kerkelijk spreken over seksualiteit en huwelijk, en: Th. Beemer y otros, Het kerkelijk spreken over seksualiteit en huwelijk. Eenbundel filosofische, gedragswetenschappelijke en theologische stdies, Nijmegen-Baarn, 238.

Sporken C.P. (1969), Voorlopige diagnose: inleiding tot een medische ethiek, Bilthoven.

Sullivan F.E. (1996), Capire e interpretare il Magistero, Bologna.

Szostek A. (1989), La concezione dell'intelletto creatore di norme. Fondamenti antropologici del rifiuto dell'Enciclica «Humanae vitae», en: AA.VV., «Humanae vitae»: 20 anni dopo, Milano, 471-513. 
Tettamanzi D. (1978), La fecondazione artificiale e alcune considerazioni morali, "Anime e Corpi" 78, 416-417.

Valsecchi A. (1968), Regulación de los nacimientos. Diez años de reflexión teológica, Salamanca.

Valsecchi A. (1974), Nuevos caminos de la ética sexual, Salamanca.

Vidal M. (1981), Moral de actitudes, I, Madrid.

Zadworny M. (2013), La recepción de la Encíclica Humanae vitae en las revistas teológicas polacas, en: Universidad de Navarra, Excerpta e Dissertationibus in Sacra Theologia, 60, Pamplona, 393-473.

Zenoni N. (2003), La trattazione dell'Enciclica Humanae vitae in alcune Reviste Theologiche Italiane, en: Universidad de Navarra, Excerpta e Dissertationibus in Sacra Theologia, 45, Pamplona, 161-278.

Augusto Sarmiento - profesor teologii moralnej. Głównym przedmiotem jego zainteresowań jest problematyka małżeństwa i rodziny, a szczególnie etyka małżeńska. Związany z Uniwersytetem Nawarry w Pampelunie (Hiszpania). Pełnił funkcję prodziekana tamtejszego Wydziału Teologicznego. Ojciec Święty Benedykt XVI mianował go konsultorem Papieskiej Rady ds. Rodziny. Pełni także funkcję konsultora podkomisji ds. rodziny i obrony życia Konferencji Episkopatu Hiszpanii. Autor wielu artykułów naukowych i monografii na temat małżeństwa i rodziny. 